\title{
A ASSESSORIA EXECUTIVA NO PROCESSO DE TOMADA DE DECISÃO
}

\section{EXECUTIVE ADVISING IN DECISION-MAKING PROCESS}

\section{Vania Silva de Souza Bilert}

Mestre em Desenvolvimento Regional pela Universidade Tecnológica Federal do Paraná - UTFPR. Professora da Universidade Estadual do Centro-Oeste - UNICENTRO.

E-mail: vaniabilert@ hotmail.com (Brasil)

\section{Adriana Aparecida Kovalski da Silva}

E-mail: adrianaksm2010@ hotmail.com (Brasil)

Juliane Aparecida Leal dos Santos

E-mail: jully_lsantos@hotmail.com (Brasil)

\section{Rosicléia Aparecida Cabral}

E-mail: rosycleyacabral@hotmail.com (Brasil) 


\title{
A ASSESSORIA EXECUTIVA NO PROCESSO DE TOMADA DE DECISÃO
}

\section{RESUMO}

Atualmente as empresas buscam profissionais cada vez mais qualificados, com perfil gerencial, para atuar nos níveis estratégicos, assessorando e participando na tomada de decisão organizacional. Com este propósito o estudo buscou compreender as relações e a influência da assessoria executiva no processo de tomada de decisão junto aos gestores da organização, devido sua atuação cada vez mais evidente no processo decisório das organizações. Assim, a pesquisa teve o objetivo de identificar a influência do profissional de Secretariado Executivo no processo de tomada de decisão e evidenciar as possíveis dificuldades no processo decisório. Com a finalidade de comprovar os questionamentos levantados, utilizou-se a abordagem qualitativa de natureza exploratória descritiva - a pesquisa caracterizou-se como um estudo de caso - para a coleta dos dados foram utilizadas pesquisas bibliográficas e aplicação de questionário para o nível estratégico de uma Associação de Guarapuava PR. Os resultados evidenciaram de forma geral que apesar de a empresa encontrar dificuldades no processo decisório, busca fazer planejamento e monitoramento dos resultados. Portanto, o profissional de Secretariado Executivo influencia neste processo, com o fornecimento de informações de qualidade e é considerado um agente facilitador por possuir conhecimentos, habilidades, visão sistêmica, assumir responsabilidades e riscos. Sua participação é fundamental.

Palavras-chave: Profissional de Secretariado Executivo; Assessoria Executiva; Processo Decisório.

\section{EXECUTIVE ADVISING IN DECISION-MAKING PROCESS}

\begin{abstract}
Nowadays, companies are looking for increasingly qualified professionals with Management Profile to act on the strategic levels, advising and participating in organizational decision making. Under this perspective, the current study sought to understand the relationship and influence of the Executive Board in decision-making process along with the managers of organizations, due to their increasing participation in these situations. In this way, the research aimed to identify the influence of the executive secretariat in professional decision-making process and to highlight the possible difficulties in decision-making. In order to prove the questions raised, a descriptive, exploratory qualitative approach was used, the research was characterized as case study, while literature research and applied questionnaire to the strategic level of the Association Guarapuava PR were used for data collection. Overall, the results showed that the company seeks to making plans and monitoring its results although difficulties are faced at the decision-making process. Therefore, the professional executive secretaries influence this process by providing quality information and it is considered a facilitator to possess knowledge, having skills, systemic view and assuming responsibilities and risks. In this case, their participation is of utmost importance.
\end{abstract}

Keywords: Executive Secretariat; Executive Advisor; Decision-Making Process.

Revista de Gestão e Secretariado - GeSec, São Paulo, v. 5, n. 3, p 119-142, set./dez. 2014. 


\section{INTRODUÇÃO}

A todo o momento as empresas precisam tomar decisões; dessa forma, necessitam de informações estruturadas para os vários níveis de decisões. Toda decisão tomada deve passar antes por um planejamento; portanto, é necessário que as informações sejam analisadas e filtradas para então agregar valor na tomada de decisão.

De acordo com estudos de Nonato Junior (2009), o profissional de Secretariado Executivo apresenta-se como gestor do conhecimento e da informação, possui várias competências, dentre elas facilidade de comunicar-se, domínio da escrita e leitura em outros idiomas, conhecimento em informática. Ele pode atuar em várias áreas da empresa, porém está sempre muito próximo do nível estratégico; dessa forma, contribui para o processo de tomada de decisão.

Neste contexto, foi abordada a relação da assessoria executiva no processo de tomada de decisão. Este estudo teve como objetivo geral analisar as relações e a influência da assessoria executiva no processo de tomada de decisão junto aos gestores da organização.

Baseando-se na necessidade de entender a relação do profissional de Secretariado Executivo no processo de tomada de decisão em uma Associação Comercial de Guarapuava PR, a pesquisa abordou as seguintes problemáticas:

Qual é a influência que o profissional de Secretariado Executivo tem no processo de tomada de decisão? O profissional de Secretariado Executivo encontra dificuldades no processo decisório?

Visando compreender esta relação, o estudo teve por objetivos específicos: compreender as relações da assessoria executiva no processo de tomada de decisão; avaliar as dificuldades dos gestores no processo decisório e como a assessoria executiva pode auxiliar neste processo; e identificar a influência da assessoria executiva na tomada de decisão diante das dificuldades encontradas pelos gestores.

Para alcançar os objetivos, inicialmente foram contextualizados quatro eixos de pesquisas bibliográficas sobre o que é o processo decisório, que segundo Oliveira (2000), implica a necessidade de uma visão ampla - o que requer conhecimento prévio das condições básicas na empresa e de seu ambiente, bem como a avaliação das consequências futuras advindas das decisões tomadas.

O segundo eixo refere-se à informação organizacional, para Lenzi e Kiezel (2009), a

Revista de Gestão e Secretariado - GeSec, São Paulo, v. 5, n. 3, p 119-142, set./dez. 2014. 
informação organizacional contribui em todo o processo decisório, a riqueza da informação serve como base para a busca de alternativas de solução, é fundamental para uma boa decisão.

O próximo eixo destaca o gestor e o processo de tomada de decisão. De acordo com Ferreira (2010), o decisor deve tratar os problemas gerenciais, levando-se em conta as diferenças e, através das percepções, usar de técnicas relacionadas ao conhecimento e de fácil comunicação, para construir uma forma de apoio ao processo de decisão.

O último eixo trata da relação da assessoria executiva na tomada de decisão; a assessoria executiva fornece a base de informações necessárias para a tomada de decisão, que conforme Nonato Junior (2009, p. 204) “o secretário trabalha na condição de assessorar atividades, cabe-lhe preparar todas as condições possíveis para o bom uso e recursos informacionais que serão gerenciados pelo executivo".

Além das pesquisas bibliográficas mencionadas, para a coleta de dados foi utilizada a aplicação de questionário para os gestores do nível estratégico da Associação, buscando resultados que justifiquem este estudo.

Portanto, a pesquisa torna-se relevante pela oportunidade de relacionar as teorias às práticas organizacionais, agregando conhecimento de práticas e rotinas, conhecendo o comportamento e postura do profissional de Secretariado Executivo, seu relacionamento com gestores e demais setores da organização, além de sua atuação nas tomadas de decisões estratégicas.

Cabe salientar que a pesquisa propiciou também um conhecimento mais aprofundado com relação às atividades do profissional de Secretariado Executivo; no que tange ao processo decisório, outro fator de relevância são conhecimentos científicos adquiridos através de pesquisas bibliográficas.

Outro fator significante para a pesquisa é a possibilidade de socialização e disseminação dos conhecimentos e resultados, subsidiando pesquisas futuras e auxiliando no aumento da produção científica na área.

Com isso o profissional de Secretariado Executivo terá mais oportunidades para desempenhar sua função com diversidade, competência, habilidades - o que agrega reconhecimento ao curso de secretariado executivo.

Revista de Gestão e Secretariado - GeSec, São Paulo, v. 5, n. 3, p 119-142, set./dez. 2014. 


\section{REFERENCIAL TEÓRICO}

Nesta seção, serão apresentados os eixos da discussão sobre processo decisório, informação organizacional e o papel do gestor e da assessoria executiva no processo de tomada de decisão.

\subsection{O PROCESSO DECISÓRIO}

O processo de tomada de decisão é importante para definir estratégias de vantagens competitivas e ações para melhor desempenho da organização, ele possui alternativas e critérios baseados em informações fundamentais para a tomada de decisão, garantindo desta forma a melhor decisão pelo gestor.

"As decisões gerenciais afetam diretamente a sobrevivência da empresa e a vida das pessoas que giram em torno dela, sejam funcionários, acionistas, fornecedores ou clientes" (Carvalho, 2011, p. 9). Nesse sentido, o processo decisório deve ter cunho holístico para assim não comprometer o desenvolvimento da organização.

Oliveira (2000), diz que o processo decisório é uma fase que necessita de uma visão ampla das alternativas que lhe afiguram, devendo ser considerado todo o conjunto complexo de consequências que poderá ser gerado como fruto da decisão.

Cassarro (2001, p. 41) define que:

\footnotetext{
Uma decisão nada mais é do que uma escolha entre alternativas, obedecendo a critérios previamente estabelecidos. Estas alternativas poderão ser os objetivos, os programas ou as políticas em uma atividade de planejamento ou os recursos, estrutura e procedimentos em uma atividade organizacional. A tomada de decisões também envolve um ciclo e é fundamental a existência de informações apropriadas a cada uma das fases do ciclo.
}

A tomada de decisão possui processo, elemento e etapas claramente definidas, entretanto, cada decisão é arriscada, um comprometimento de recursos presentes com um futuro incerto. Por isso, antes de tomar uma decisão é necessário observar cuidadosamente o processo e tomar as medidas necessárias (Drucker \& Maciariello, 2007).

Os autores Hitt; Miller; Colella (2007, p. 288) propõem um processo de tomada de decisão que envolve seis etapas, descritas na figura 1:

Revista de Gestão e Secretariado - GeSec, São Paulo, v. 5, n. 3, p 119-142, set./dez. 2014. 
Figura 1 - O processo de tomada de decisão

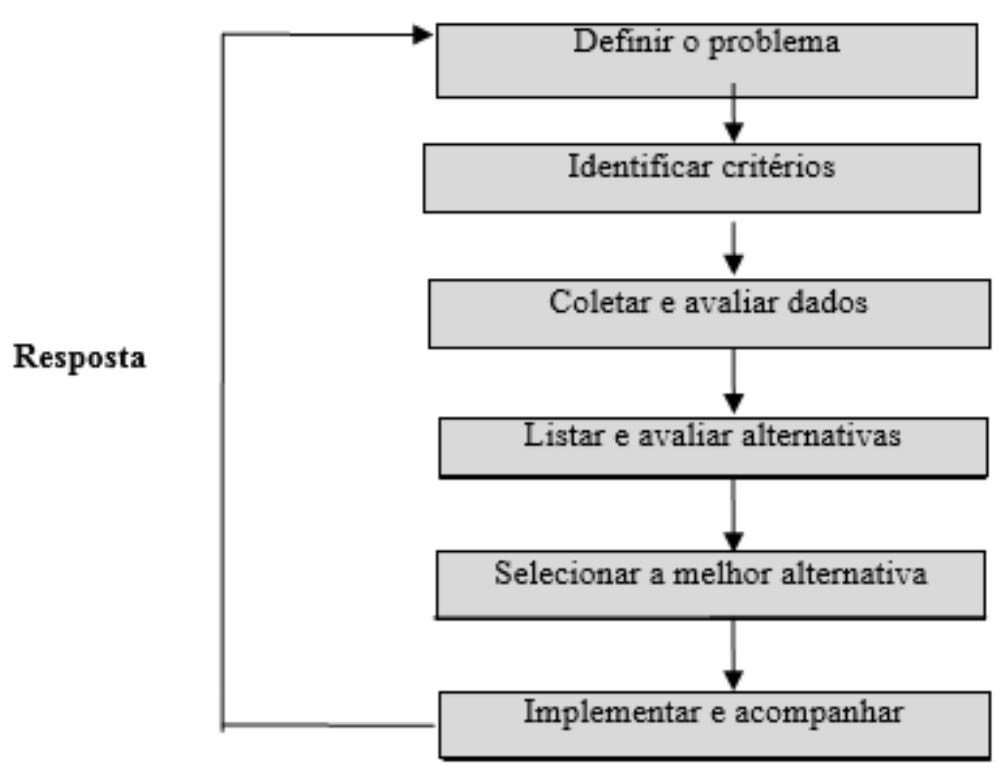

Fonte: Adaptado de Hitt; Miller; Colella (2007, p. 288).

Na primeira etapa é definido o problema a ser solucionado, de modo geral são lacunas de onde estamos hoje e onde gostaríamos de estar amanhã. O autor afirma que definições estritas para os problemas representam um importante fator de preocupação na tomada de decisão, uma vez que restringem o número de opções.

Na etapa seguinte Hitt; Miller; Colella (2007) identificam os critérios de decisão, sendo necessário que a pessoa determine exatamente o que deseja ao solucionar o problema. Assim, determinam quais informações o tomador de decisão precisa coletar para avaliar alternativas, e ajudá-lo a explicar a escolha que poderá tomar.

$\mathrm{Na}$ sequência, os autores afirmam que o tomador de decisão deve coletar e processar informações para melhor compreender o contexto da decisão e descobrir alternativas que possam solucionar o problema.

Por conseguinte Hitt; Miller; Colella (2007) mencionam que o tomador de decisão irá identificar e avaliar todas as alternativas relevantes; deve avaliar, portanto, cada uma delas e utilizar cada um dos critérios. Após avaliar cada alternativa, o tomador de decisão escolhe aquela que melhor satisfaça aos critérios.

O processo de decisão compreende questionamentos e definição de ações concretas. Dentre os elementos que compõem o processo decisório destacam-se as informações, que embasam os questionamentos e a definição de ações alternativas, e o tomador de decisão, que concretiza as atitudes (Freitas, 1997).

Revista de Gestão e Secretariado - GeSec, São Paulo, v. 5, n. 3, p 119-142, set./dez. 2014. 
Os estudos de Oliveira (2000) comprovam que alguns fatores influenciam o processo de tomada de decisão: a complexidade evolutiva do mundo moderno; redução do tempo disponível para a tomada de decisão, pela influência de algumas variáveis; velocidade de comunicações e melhoramento nos processos de informações, com expectativa de resultados em curto prazo.

O referido autor também evidencia alguns elementos importantes a serem considerados no processo decisório: a incerteza, que ocorre na situação do ambiente que envolve a decisão, na identificação e valoração das consequências decorrentes da opção; os recursos do tomador de decisão, que normalmente são limitados e que prejudicam a ação.

Observou-se que a tomada de decisão para ser eficiente deve considerar os elementos essenciais. Além disso, deve ter um estruturado processo informacional (apresentado no próximo tópico).

\subsection{INFORMAÇÃO ORGANIZACIONAL}

A informação é um importantíssimo fator em qualquer gestão organizacional; portanto, o acesso à informação e a capacidade de extrair e aplicar os conhecimentos são essenciais para o aumento da capacidade competitiva e desenvolvimento das organizações.

A respeito disso, Beuren (2000) afirma que o propósito da informação é capacitar os gestores a alcançar os objetivos da organização com o uso eficiente de seus recursos. Desse modo, conceitos de mensuração da informação são importantes, visto que os dados são coletados, processados, acumulados e comunicados às empresas.

Beuren (2000, p.43) destaca que:

A informação é fundamental no apoio às estratégias e processos de tomada de decisão, bem como no controle das operações empresariais. Sua utilização representa uma intervenção no processo de gestão, podendo inclusive, provocar mudança organizacional, à medida que afeta os diversos elementos que compõem o sistema de gestão.

Portanto, por meio da maturidade e qualidade da informação é que são direcionadas as decisões e ações estratégicas na organização, visando à decisão mais coerente para o sistema de gestão.

Para Beuren (2000) nem todas as informações apresentam a mesma importância para uma tomada de decisão. Umas são mais relevantes que as outras; a relevância é, pois, o grau de importância que uma informação possui para a tomada de decisão.

Revista de Gestão e Secretariado - GeSec, São Paulo, v. 5, n. 3, p 119-142, set./dez. 2014. 
Os benefícios de uma tomada de decisão com inteligência são percebidos claramente, e é necessário adotar uma abordagem estratégica para essa tomada de decisão. Enquanto estiver tomando as decisões, é necessário processar informações e identificar dados relevantes para evitar o excesso de informações (School, 2007).

Segundo a análise de Porto (2004) a decisão de cooperação é racional. As incertezas consideradas mais relevantes no processo decisório são aquelas associadas à busca de um mecanismo de coleta e análise das informações, e quando ocorre a cooperação o acesso às informações é permitido a todos os envolvidos, com espaço para críticas e opiniões - o que contribui para a decisão final visando o alcance dos objetivos.

A contribuição da informação é importante para todos os níveis da organização compreendendo várias áreas de gestão. Dessa forma, Beuren (2000) define as principais áreas usuárias das informações como sendo gestores dos mais diversos níveis, assessores de executivos, profissionais de pesquisa, desenvolvimento, marketing, acionistas, investidores potenciais, instituições financeiras, clientes, concorrentes, fornecedores, analistas de mercado, entre outros. As necessidades de informações destes profissionais são muitas vezes, variadas e interfuncionais.

Além das informações, o processo decisório depende de uma comunicação eficiente para a tomada de decisão. De acordo com School (2007), a comunicação desempenha um papel importante na tomada de decisão; por isso, é interessante conciliar pontos de vista opostos, examinar o raciocínio lógico das escolhas com outras pessoas para assim identificar e corrigir erros.

\footnotetext{
A comunicação exerce um papel importante nesse processo e é o canal utilizado para auxiliar na tomada de decisão, pois envolve a troca e informações entre agentes. Essa troca de informações deve ocorrer tanto no sentido vertical (ascendente ou descendente) e horizontal (no mesmo nível hierárquico) quanto no diagonal (entre pessoas que atuam em níveis hierárquicos diferentes). (Starec; Gomes \& Bezerra, 2005, p.199).
}

A interação da comunicação é essencial para o conhecimento e disseminação da informação organizacional. Os estudos de Hitt; Miller e Colella (2007) identificam que os membros de uma equipe devem se comunicar, para que coordenem com eficácia seus esforços produtivos. As instruções devem ser repassadas, os resultados relatados, sendo necessária uma discussão sobre resolução de problemas.

Os autores supracitados afirmam que a comunicação é crucial para as equipes criarem processos formais de comunicação, os quais podem incluir relatórios e reuniões formais, cronogramas de trabalho e memorando internos.

Sendo assim destaca-se que tais processos se relacionam com as funções da assessoria 
executiva, que auxiliam o gestor no processo de tomada de decisão, que será contextualizado a seguir.

\subsection{O GESTOR E O PROCESSO DE TOMADA DE DECISÃO}

Para a tomada de decisão é necessário que os gestores tenham planejamento e estratégias definidas, pois o sucesso da decisão do gestor depende de um processo estruturado interligando as partes envolvidas.

Oliveira (2000) ressalta que o sucesso de uma decisão depende de um processo de escolha adequado como: a identificação e análise do problema, com base na consolidação das informações, interligando todas as partes do problema; estabelecimento de soluções; análise e comparação das soluções alternativas, por meio de levantamentos das vantagens e desvantagens em relação ao grau de eficiência, eficácia e efetividade do processo.

O autor afirma também que é necessária a seleção da alternativa adequada, a implantação da alternativa selecionada, incluindo treinamento e capacitação das pessoas envolvidas, avaliação da alternativa por meio de critérios e parâmetros devidamente aceitos pela empresa.

Os processos gerenciais estão relacionados à utilização de técnicas de planejamento, controle e canais de comunicação para facilitar o fluxo da informação, a definição de responsabilidades dos setores e das pessoas, à forma como a autoridade é exercida, aos sistemas de recompensa e aos padrões de qualidade e produtividade (Starec; Gomes \& Bezerra, 2005).

O planejamento ajuda a criar estruturas para o processo da tomada de decisão. O planejamento define as atividades que orientam a vinculação de recursos e o desempenho da empresa. A falta de planejamento pode acarretar diversas perdas em diferentes setores. Para as grandes empresas, a falta de planejamento pode gerar prejuízo financeiro, para as pequenas empresas, imagina-se que o prejuízo pode ser maior (Carvalho 2011, p.13).

Além do planejamento no processo decisório, Ferreira (2010) salienta que o decisor deve tratar os problemas gerenciais levando em conta as diferenças e através das percepções usar de técnicas relacionadas ao conhecimento - e de fácil comunicação - para construir uma forma de apoio ao processo de decisão. Assim, ele pode resolver as dificuldades e trazer novas percepções de julgamento e tomada de decisão.

Segundo Oliveira (2000) o conhecimento é adquirido pelas informações que o tomador dispõe sobre as operações da empresa, seus concorrentes, fornecedores, mercado financeiro,

Revista de Gestão e Secretariado - GeSec, São Paulo, v. 5, n. 3, p 119-142, set./dez. 2014. 
mercado de mão de obra, decisões governamentais.

Ainda conforme o entendimento do autor, a decisão pode ser tomada sob determinadas condições de certeza, em que cada curso de ação conduz a um resultado específico e cada alternativa leva a um conjunto de resultados associados a probabilidades conhecidas e condições de incertezas.

Observa-se que é importante o envolvimento dos funcionários no processo decisório. Portanto Hitt; Miller e Colella (2007) afirmam que os gestores devem determinar o nível certo de envolvimento do funcionário no processo de tomada de decisão. Deve diagnosticar a situação do problema e em seguida determinar até que ponto os funcionários serão envolvidos no processo de tomada de decisão.

Os autores destacam que a extensão do envolvimento depende do efeito que a participação pode ter em relação à qualidade esperada da decisão, aceitação ou comprometimento dos funcionários necessários para a implementação da solução, e o tempo disponível e necessário para se tomar a decisão.

Portanto, faz-se necessário o envolvimento do assessor executivo que detém todas as informações necessárias para a tomada de decisão, pois é considerado um gestor da informação e do conhecimento na organização, conforme será abordado no próximo eixo.

\subsection{A ASSESSORIA EXECUTIVA E A TOMADA DE DECISÃo}

Atualmente o mundo globalizado tornou-se ágil, dinâmico e prático, fazendo com que o perfil do profissional de secretariado se aprimorasse agregando novas competências para acompanhar estas tendências. O profissional de Secretariado Executivo deve estar preparado para atuar em múltiplas atividades, assumindo um papel importante dentro das organizações, gerenciando informações e assessorando os gestores para a tomada de decisões. Dessa forma, ele desempenha sua função com competência, tornando-se cada vez mais um diferencial para o mundo competitivo.

O secretário trabalha na condição de assessorar atividades, cabe-lhe preparar todas as condições possíveis para o bom uso e recursos informacionais que serão gerenciados pelo executivo. Assim, seu fluxo de gestão se caracteriza, sobretudo, pela abertura, introdução e planejamento dos vários processos de informação que serão encaminhados ao executivo (Nonato Junior, 2009, pp. 204-205).

Portanto, percebe-se que o profissional de secretariado exerce um importante papel nas

Revista de Gestão e Secretariado - GeSec, São Paulo, v. 5, n. 3, p 119-142, set./dez. 2014. 
organizações, está próximo do nível estratégico, e contribui para o processo de tomada de decisão.

Segundo Nonato Junior (2009), a Assessorexe (Assessoria Executiva) é um dos eixos da assessoria que está ligada às questões de trabalho de assessoria empresarial, oficial ou gerencial, com seu foco sobre o fluxo informacional gerenciado nas atividades de assessoria executiva.

De acordo com Mascarenhas; Sepulveda e D’Assumpção (2011), a participação do secretário executivo nos processos de gestão está diretamente relacionada à assessoria de seu gestor; dessa forma é importante o conhecimento, envolvimento e monitoramento do profissional secretário em todos os processos.

Atualmente não é mais atribuído ao profissional secretário executivo somente tarefas rotineiras e atividades técnicas. Para Nonato Junior (2009) o Secretariado Executivo vem demonstrando novas significações sobre o uso e abordagem da gestão informacional. Nesse sentido, é importante que o profissional de Secretariado Executivo conceba a informação, não apenas como um mero produto, compreendendo a complexidade do seu processo.

O gerenciamento da documentação e informação consiste na técnica de recepção, interpretação, análise, difusão, armazenamento e manutenção de toda e qualquer informação emitida ou recebida pela organização. Essa técnica é fundamental para a manutenção de qualquer outra técnica secretarial, visto que o profissional de Secretariado Executivo é intermediador do processo e esses são alimentados pela informação (Bortolotto \& Willers, 2003).

Esses autores enfatizam que o profissional de Secretariado Executivo deve conhecer a missão da organização, fazer o levantamento de dados informacionais e dos fluxos adequados para atender as necessidades do processo, desenvolver um sistema informal que prevê o tratamento da informação desde sua recepção até seu descarte.

Segundo Beuren (2000), apud Dopico, Rodrigues e Stolle (1995), uma das relações mais importantes em uma organização é entre quem elabora, interpreta e comunica a informação e a pessoa que relaciona alternativa, toma as decisões e é o responsável por elas. O primeiro seleciona e desenha um sistema de informações para fornecer a informação ao segundo, o qual a utiliza para tomar decisões.

Bruno (2006) atesta que o profissional de secretariado acompanha as mudanças impostas pelo processo da globalização, bem como a horizontalizacão gerencial e agrega novas competências ao seu perfil, possibilitando participar efetivamente da equipe de trabalho e não somente como coadjuvante. 
Dentro desta realidade, é possível entender o profissional de Secretariado Executivo como coparticipante na gestão de processos e responsável por contribuir nas tomadas de decisões na organização. Devido ao perfil polivalente e multifuncional este profissional é capaz de ser flexível, atuante e mediador nas relações organizacionais, atuando como facilitador dos processos (Mascarenhas; Sepulveda \& D’assumpção 2011, p.190).

Devido ao seu perfil polivalente, o profissional de secretariado possui conhecimento e competência para atuar nas mais diversas áreas como: assessoria de recursos humanos, marketing, gestão da informação, gestão estratégica, assessoria no comércio exterior, consultorias, entre outras. Portanto, o profissional secretário executivo exerce um papel fundamental na organização, pois se relaciona com todos os setores da organização e possui as informações estratégicas para a tomada de decisão.

\section{METODOLOGIA}

Neste item encontra-se a construção metodológica da pesquisa e dos critérios de sua realização que teve por objetivo analisar as relações e influências da assessoria executiva no processo de tomada de decisão junto aos presidentes e gestores de uma Associação na cidade Guarapuava-PR.

A pesquisa classifica-se na abordagem qualitativa; nesta abordagem são estudados fenômenos típicos das Ciências Sociais (Appolinário, 2009). É de natureza exploratória descritiva que, segundo Gil (2009), tem como objetivo proporcionar maior familiaridade com o problema e torná-lo mais explícito, aprimorar ideias ou descoberta de intuições.

Ainda na concepção do autor, na maioria dos casos estas pesquisas envolvem levantamento bibliográfico, entrevista com pessoas que tiveram experiências práticas com o problema pesquisado e análise de exemplos que estimulem a compreensão; embora seja bastante flexível, pode assumir a forma de pesquisa bibliográfica e estudo de caso.

No entendimento de Gil (2009), a pesquisa descritiva é a descrição de características de determinada população ou fenômeno ou estabelecimento de relações entre variáveis, sua característica mais significativa está na utilização de técnicas padronizadas de coletas de dados, tais como questionários e observação sistemática. Porém, pesquisas definidas como descritivas com base nos seus objetivos, acabam servindo mais para proporcionar uma nova visão do problema, o que as aproxima das pesquisas exploratórias.

A pesquisa foi realizada em uma Associação Comercial de Guarapuava-PR e trata de um

Revista de Gestão e Secretariado - GeSec, São Paulo, v. 5, n. 3, p 119-142, set./dez. 2014. 
de estudo de caso. De acordo com Oliveira (2010), a aplicação do método de estudo de caso deve ser utilizado para atender os objetivos preestabelecidos pelos pesquisadores como sendo o estudo apropriado a fim de buscar fundamentos e explicações para determinado fato ou fenômeno da realidade empírica.

O nível estratégico da Associação é composto pelo presidente da Associação de Guarapuava-PR e da Associação Regional e pelo comitê administrativo do qual fazem parte oito gestores conforme apresentado a seguir:

\begin{tabular}{|l|l|}
\hline \multirow{2}{*}{ PRESIDENTES } & Associação de Guarapuava-PR \\
\cline { 2 - 2 } & Associação Regional \\
\hline \multirow{4}{*}{ GESTORES } & Recepção \\
\hline & Financeiro \\
\cline { 2 - 2 } & Recursos Humanos \\
\cline { 2 - 2 } & DEA \\
\cline { 2 - 2 } & SPC \\
\hline & Junta Comercial \\
\cline { 2 - 2 } & Comercial \\
\cline { 2 - 2 } & Secretaria \\
\hline
\end{tabular}

Quadro 1. População pesquisada.

Fonte: Elaborado pelas autoras (2013).

Para a coleta dos dados foram utilizadas estratégias como pesquisas bibliográficas com consulta em livros e artigos científicos referentes ao tema, "Assessoria Executiva no Processo de Tomada de Decisão”. De acordo com Oliveira (2010), a pesquisa bibliográfica faz com que o pesquisador entre em contato direto com obras, artigos ou documentos que tratem do tema em estudo.

A pesquisa de campo foi realizada por meio de aplicação de questionário com quatorze questões para os dez integrantes da população pesquisada conforme citado anteriormente, porém, obteve-se retorno de nove gestores. Para o setor da secretaria, coordenado pelo profissional de Secretariado Executivo, foi aplicado o mesmo método, porém com algumas questões diferenciadas, visando identificar sua atuação no processo de tomada de decisão.

Questionário é um instrumento de coleta de dados que pode ser utilizado para obter informações acerca de grupos sociais, tem como função descrever as características e medir determinadas variáveis de um indivíduo ou grupo. Uma descrição adequada das características de um grupo não apenas beneficia a análise a ser feita por um pesquisador, mas também pode

Revista de Gestão e Secretariado - GeSec, São Paulo, v. 5, n. 3, p 119-142, set./dez. 2014. 
ajudar outros especialistas, planejadores, administradores e outros (Richardson, 2008).

Para descobrir possíveis falhas no método de coleta de dados foi realizado um pré-teste dos questionários, com dois gestores de uma empresa de Guarapuava-PR, para verificar a clareza das questões - após concluir que as questões estavam de fácil entendimento e coerentes, os questionários foram aplicados. Segundo Gil (2010) pré-teste está centrado na avaliação dos instrumentos, visando garantir que meçam exatamente o que pretendem medir.

Por se tratar de pesquisa qualitativa, na construção das perguntas utilizou-se a escala não métrica de cinco pontos, ou seja, com cinco categorias de respostas, apresentado expressões descritivas com: sempre, quase sempre, às vezes, raramente, nunca (Hair Jr. et al., 2005).

Como procedimento de análise de dados, utilizou-se análise descritiva por meio de quatro categorias: processo decisório na organização; a eficácia da informação organizacional; o gestor e o processo de tomada de decisão; e a assessoria executiva e a tomada de decisão.

De acordo com Minayo, Deslandes e Gomes (2007), a interpretação dos dados coletados por meio do questionário, tem como principal objetivo avaliar, comparar e selecionar as ideias principais para atingir o objetivo proposto neste trabalho.

Após apresentação metodológica, para alcançar os objetivos de pesquisa será apresentada a análise e sistematização dos dados obtidos procedendo à interpretação qualitativa.

\section{ANÁLISE DE DADOS}

As análises de dados referem-se à contextualização entre as relações da assessoria executiva no processo de tomada de decisão organizacional. Os resultados foram obtidos por meio de questionário aplicado ao nível estratégico da associação, que é composto por presidentes e gestores do comitê administrativo.

Para a análise e interpretação dos resultados foram abordadas categorias no que se refere ao funcionamento do processo decisório na organização, a eficácia da informação organizacional e o papel do gestor e da assessoria executiva no processo de tomada de decisão.

\subsection{PROCESSO DECISÓRIO}

Esta categoria visa analisar as dificuldades dos gestores e do profissional de Secretariado Executivo em relação ao processo decisório e a falta de informação, busca identificar se a Revista de Gestão e Secretariado - GeSec, São Paulo, v. 5, n. 3, p 119-142, set./dez. 2014. 
organização utiliza planejamento e estratégias definidas para este processo.

Em relação ao planejamento e estratégias definidas identificou-se que a classificação "sempre" foi apontada por quatro dos gestores - considera-se, portanto, que a empresa possui uma organização para a tomada de decisão.

Questionados se existem dificuldades no processo decisório, a classificação "às vezes" foi a mais apontada pelos pesquisados. Isso denota que em certos momentos os gestores encontram dificuldades e estas dificuldades estão relacionadas com a falta de informações; além da falta de informações observam-se outras dificuldades relacionadas ao processo decisório, entretanto, não evidenciadas nesta pesquisa.

Conforme Beal (2007), a informação possibilita a redução da incerteza na tomada de decisão, e a qualidade das decisões dependerá tanto da qualidade da informação provida quanto da capacidade dos tomadores de decisão de interpretá-la e usá-la na escolha das melhores alternativas.

As análises apontadas sobre o processo decisório da organização serão representadas conforme gráfico 1 .

\section{Gráfico 1 - Processo decisório}

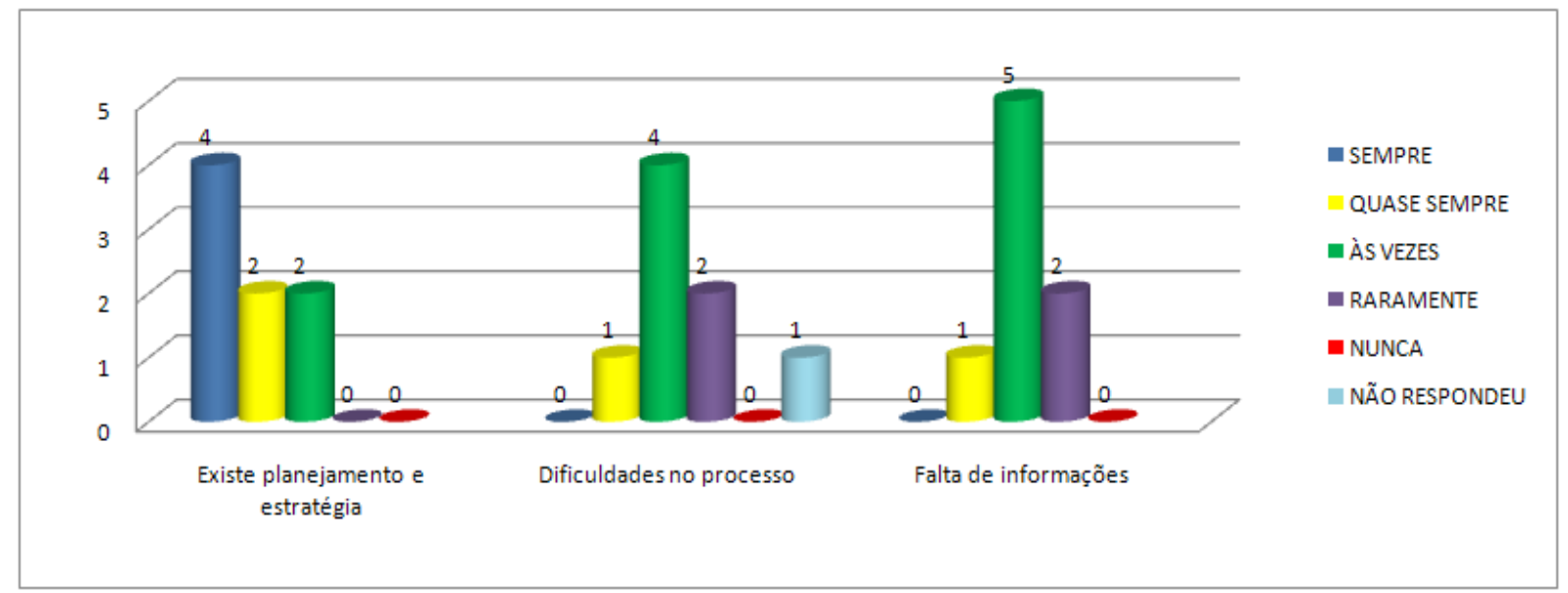

Fonte: Elaborado pelas autoras (2013).

Os mesmos questionamentos foram direcionados para o profissional de Secretariado Executivo que considerou que "quase sempre" a empresa possui planejamento e estratégias definidas para o processo decisório. Sobre as dificuldades, o profissional afirma que "às vezes" são encontradas dificuldades neste processo e "quase sempre" estas dificuldades estão relacionadas à

Revista de Gestão e Secretariado - GeSec, São Paulo, v. 5, n. 3, p 119-142, set./dez. 2014. 
falta de informações. Observa-se então, que as concepções entre gestores e o profissional de Secretariado Executivo estão alinhados.

Com base no observado, afirma-se que a empresa busca planejar as ações, apesar de ainda encontrar dificuldades no processo decisório, que pode ser ocasionado pela falta de informação.

\subsection{INFORMAÇÃO ORGANIZACIONAL}

Em relação à informação organizacional, esta categoria visa analisar os dados informacionais disponibilizados para o processo decisório e a qualidade da informação.

No que se refere à qualidade das informações disponibilizadas para o processo decisório, evidenciou-se a classificação "quase sempre" pela maioria dos gestores pesquisados, percebe-se que as informações são disponibilizadas com qualidade, o que é fundamental para tomada de decisão na organização.

Neste sentido, Porto (2004) enfatiza que a informação é a base para tomada de decisão e sua qualidade é fundamental para que o processo ocorra de forma eficiente, em termos da sua disponibilidade e qualidade; é isso que vai permitir ao decisor realizar a escolha mais apropriada, tanto na decisão individual quanto em grupo.

Sobre as informações disponibilizadas para o processo decisório, segundo quatro dos pesquisados "às vezes" estas informações são disponibilizadas pelo profissional de Secretariado Executivo. Isso denota que o processo decisório poderia ser mais eficaz se as informações "sempre" fossem disponibilizadas por este profissional, pois ele é considerado como gestor da informação e do conhecimento. De acordo com Nonato Junior (2009), o profissional vem demonstrando novas significações sobre o uso e abordagem da gestão informacional. Nesse contexto, o assessor apresenta-se como gestor do conhecimento, estudando não apenas a operacionalização técnicotática das ações secretariais e sim a dimensão estratégica.

No gráfico 2 serão apresentadas a evidência da disponibilidade e a qualidade da informação organizacional. 
Gráfico 2- Informação organizacional.

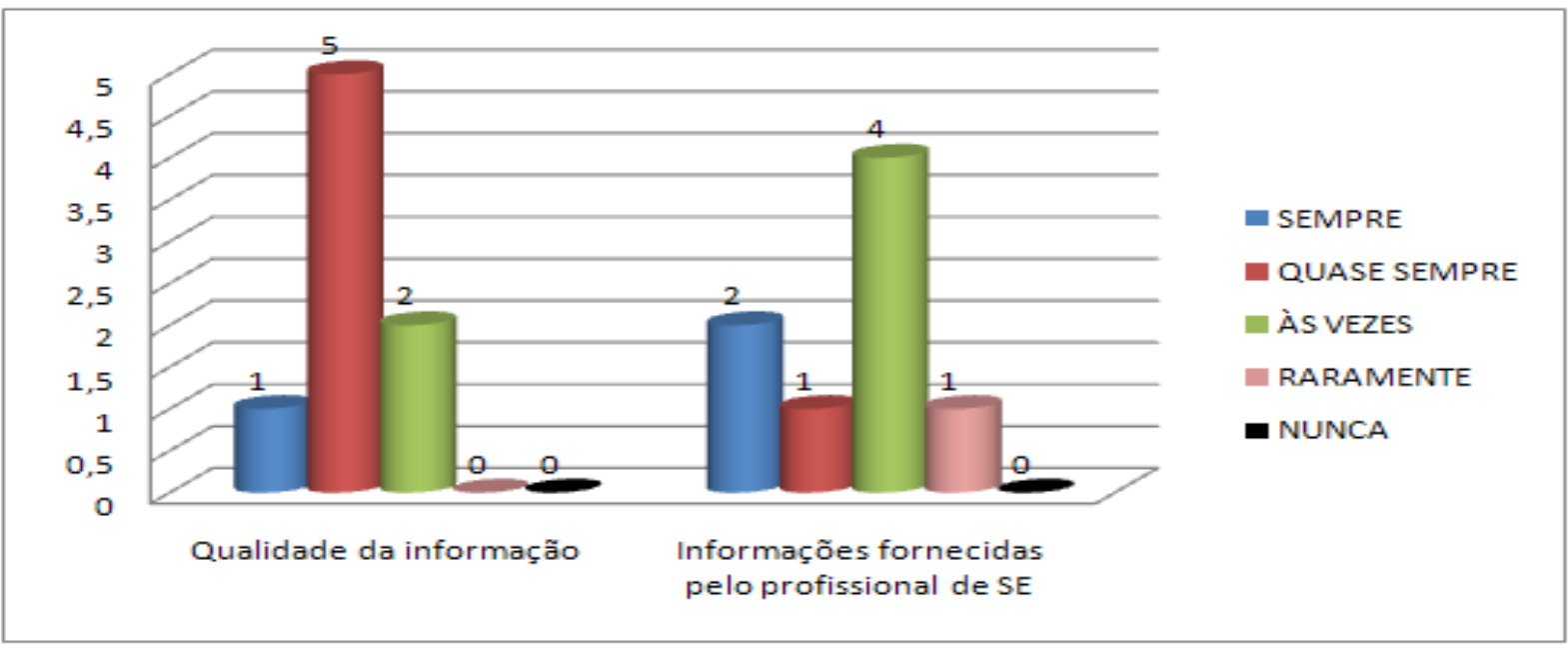

Fonte: Elaborado pelas autoras (2013).

O profissional de Secretariado Executivo quando questionado sobre as questões apresentadas nesta categoria, afirma que "quase sempre” as informações são disponibilizadas para o processo decisório, é ele quem disponibiliza estas informações, no que diz respeito ao processo de assessoria executiva direta aos presidentes da Associação, o que não está relacionado com os demais gestores da organização, conforme evidenciado na análise anterior.

Constata-se, portanto, uma contradição nas respostas, enquanto os gestores afirmaram que "às vezes" as informações são disponibilizadas pelo profissional de Secretariado Executivo; o profissional afirmou que "quase sempre" disponibiliza -, , pode-se inferir, então, que a assessoria do profissional de Secretariado Executivo está mais direcionada à presidência da Associação.

\subsection{O GESTOR E O PROCESSO DE TOMADA DE DECISÃO}

A seguir serão apresentados os resultados da tomada de decisão organizacional e a relação deste processo com os demais setores.

A tomada de decisão geralmente reflete em toda a organização, quando indagados se o processo decisório tem ênfase com os demais setores da organização, a classificação "às vezes" foi evidenciada por quatro dos gestores.

Com referência ao monitoramento e acompanhamento dos resultados das decisões tomadas na organização quatro gestores responderam que "sempre" é feito o acompanhamento. A decisão

Revista de Gestão e Secretariado - GeSec, São Paulo, v. 5, n. 3, p 119-142, set./dez. 2014. 
deve ser implementada, acompanhada e monitorar seus resultados para certificar-se de que a alternativa adotada solucionou o problema - o processo não termina quando a decisão é tomada (Hitt; Miller \& Colella, 2007).

As evidências apontadas nesta categoria mostram que as decisões tomadas têm ênfase com todos os setores da organização e após as decisões tomadas é realizado monitoramento para garantir eficácia dos resultados, o que evidencia o gráfico 3.

Gráfico 3 - Gestor e o processo de tomada de decisão.

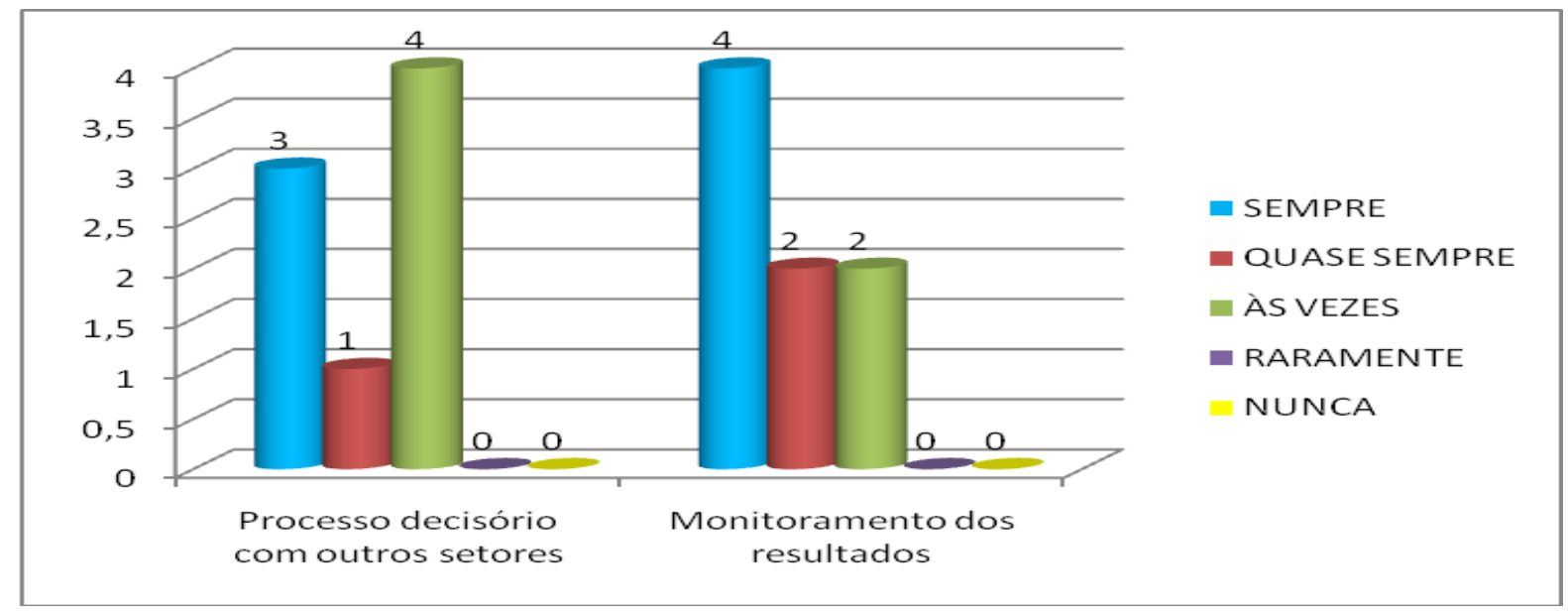

Fonte: Elaborado pelas autoras (2013).

$\mathrm{Na}$ opinião do profissional de Secretariado Executivo em relação aos temas abordados, respondeu que "quase sempre" o processo decisório possui relações com outros setores e que é feito monitoramento para acompanhar os resultados.

\subsection{ASSESSORIA EXECUTIVA E A TOMADA DE DECISÃO}

Nesta categoria foram abordadas questões relacionadas ao profissional de Secretariado Executivo e sua atuação no processo de tomada de decisão.

Em relação à participação do profissional de Secretariado Executivo como agente facilitador no processo de tomada de decisão, a classificação "quase sempre" foi evidenciada por três gestores. Quando questionados sobre o envolvimento do profissional no processo decisório, a maioria dos gestores afirmou que quando envolvido tem responsabilidades e assume riscos. Tal resultado vai ao encontro da constatação de Bruno (2006), pois é exigido deste profissional papel de gestor, empreendedor e assessor com a responsabilidade em assumir riscos e participar efetivamente da

Revista de Gestão e Secretariado - GeSec, São Paulo, v. 5, n. 3, p 119-142, set./dez. 2014. 
dinâmica organizacional, influenciando inclusive o processo decisório.

Procurando entender um pouco mais sobre os conhecimentos do profissional de Secretariado Executivo, foi perguntado aos pesquisados se eles possuem conhecimentos e habilidades necessárias para tomada de decisão. A classificação que mais sobressaiu foi "às vezes".

Outro fato interessante para a pesquisa foi que segundo a maioria dos gestores, o profissional possui visão sistêmica da organização. Bruno (2006) ressalta que o profissional de Secretariado Executivo tem uma posição estratégica, pois tem acesso às informações e a uma visão sistêmica do processo organizacional, o que possibilita a articulação de dados e informações no assessoramento, e consequentemente influencia no processo decisório.

Os resultados abordados neste tópico serão representados no gráfico 4.

Gráfico 4 - Assessoria executiva e a tomada de decisão.

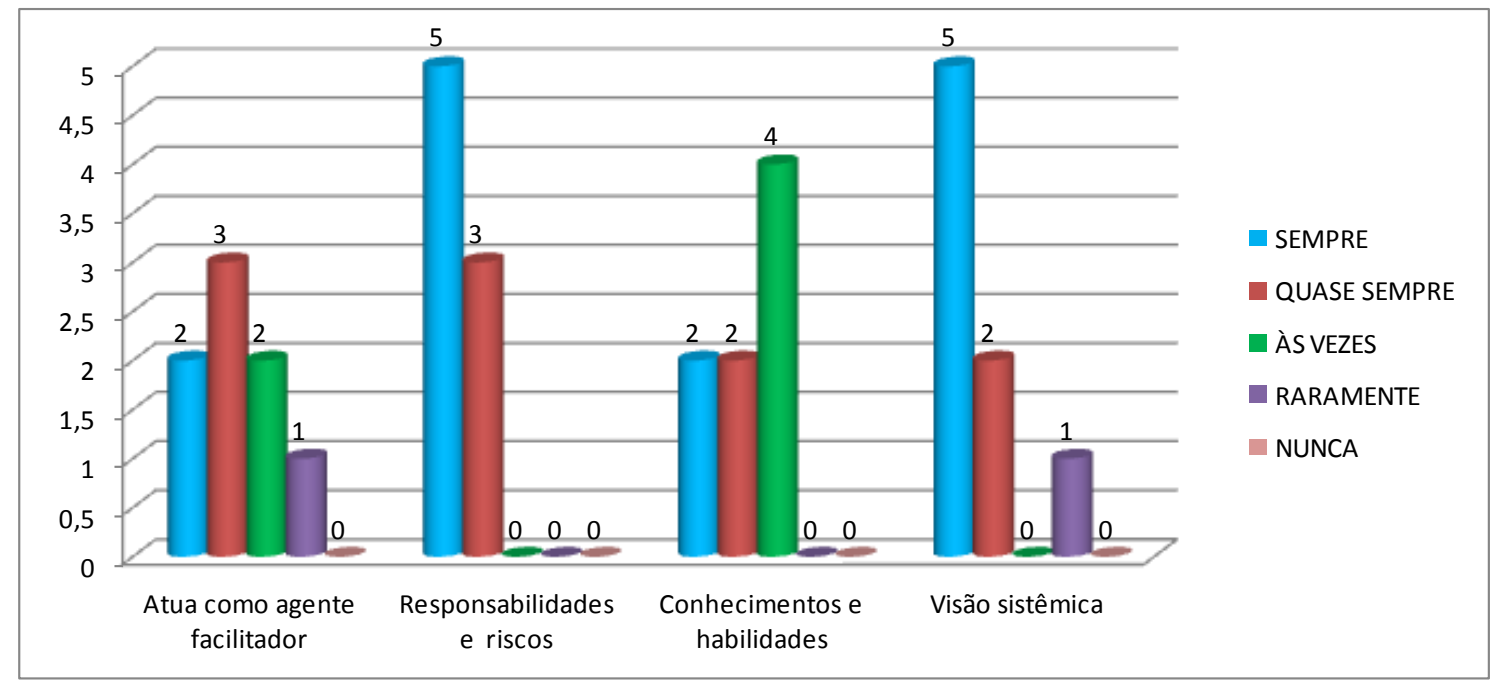

Fonte: Elaborado pelas autoras (2013).

Sobre sua atuação na organização, o profissional de Secretariado Executivo considera-se um agente facilitador no processo de tomada de decisão e quando envolvido no processo tem responsabilidades e assume riscos. Nesse sentido, de acordo com o entendimento de Mascarenhas; Sepulveda e Dessumpção (2011), o profissional de Secretariado Executivo atua como coparticipante e mediador nas relações organizacionais. Na gestão de processos é responsável por contribuir nas tomadas de decisões ao atuar como agente facilitador dos processos devido ao seu perfil polivalente e multifuncional.

O profissional de Secretariado Executivo considera também que "sempre" possui

Revista de Gestão e Secretariado - GeSec, São Paulo, v. 5, n. 3, p 119-142, set./dez. 2014. 
conhecimento e habilidades necessários para a tomada de decisão na organização. Em relação à visão sistêmica da organização, o profissional afirma que "quase sempre" possui conhecimentos gerais sobre a organização. Isso indica que o profissional possui habilidades e responsabilidade para atuar junto ao processo decisório, visto seu perfil multifuncional.

No gráfico 5 serão apresentadas questões relacionadas à participação do profissional de Secretariado Executivo no processo decisório.

Gráfico 5 - Atuação da assessoria executiva no processo decisório.

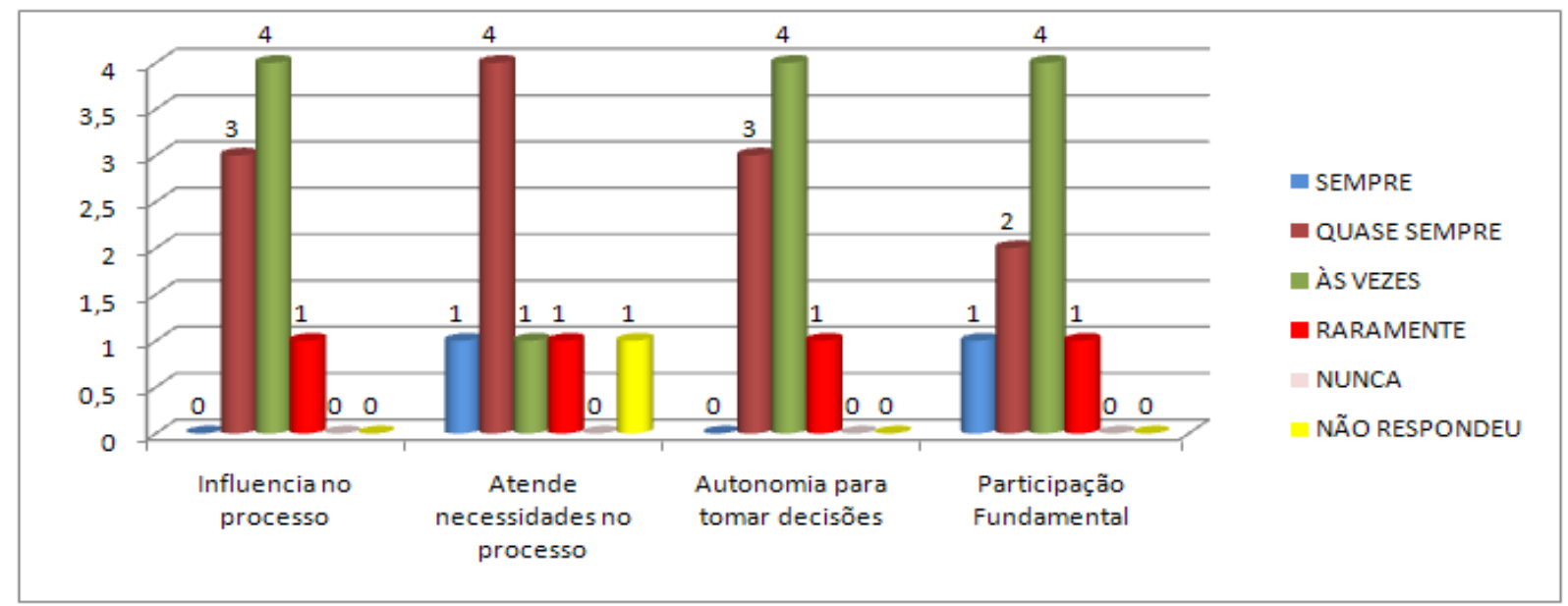

Fonte: Elaborado pelas autoras (2013).

Quando indagados sobre a influência do profissional no processo decisório, a maioria dos gestores considera que "às vezes" o profissional influencia nesse processo e "quase sempre" atende as necessidades do processo de tomada de decisão, segundo o ponto de vista de quatro gestores pesquisados.

Tratando-se da autonomia do profissional de Secretariado Executivo para tomar decisões, os gestores da organização entendem que "às vezes" o profissional tem autonomia para tomar as decisões, visto que sua participação é fundamental nos processos, devido sua articulação com os setores da organização.

Com referência à opinião do profissional de Secretariado Executivo sobre as questões relacionadas à sua participação no processo de tomada de decisão, afirma que "quase sempre" influencia no processo por atender as necessidades fundamentais do processo de tomada de decisão. Ele atesta que "sempre" é delegada autonomia para tomar decisões quando necessário.

Do ponto de vista do profissional de Secretariado Executivo "quase sempre" sua participação é fundamental para a tomada de decisão, pois sua opinião é acatada pelos demais

Revista de Gestão e Secretariado - GeSec, São Paulo, v. 5, n. 3, p 119-142, set./dez. 2014. 
gestores, devido "sempre" ter segurança para expor suas ideias na resolução dos problemas e conflitos da empresa.

Com as mudanças ocorridas na atuação do profissional de secretariado no mercado de trabalho, este profissional assume cada vez mais responsabilidades, compatíveis com a sua importância, exercita a liderança, utiliza a criatividade, a comunicação, o equilíbrio emocional e adquire capacidade de assessorar e exercer o papel de cogestor nos processos decisórios (Almeida; Rogel \& Shimoura, 2010).

As análises apontadas evidenciaram que a empresa pesquisada possui planejamento estratégico, e qualidade nas informações, porém encontram algumas dificuldades no processo decisório, a empresa visa melhores resultados realizando monitoramento das decisões tomadas.

Os gestores consideram que o profissional de Secretariado Executivo atua como agente facilitador, tem responsabilidade e assume riscos, possui autonomia, habilidades e visão sistêmica para atuar e influenciar no processo decisório.

A seguir serão apresentadas as considerações finais relacionando com os objetivos propostos e respondendo as problemáticas apresentadas neste estudo.

\section{CONSIDERAÇÕES FINAIS}

O profissional de Secretariado Executivo, cada vez mais, vem evidenciando-se na tomada de decisão das organizações. Este trabalho visou relacionar a assessoria executiva no processo de tomada de decisão em uma Associação de Guarapuava-PR, e teve como objetivo analisar as relações e a influência do profissional de Secretariado Executivo junto aos gestores desta organização.

Para responder à problemática e alcançar os objetivos específicos da pesquisa, no que se refere à influência do profissional de secretariado no processo de tomada de decisão, os resultados evidenciaram de forma geral que o profissional de Secretariado Executivo possui influência nesse processo, pois sua participação é fundamental para a tomada de decisão, sua opinião é acatada pelos demais gestores e ele tem segurança para expor ideias na resolução dos problemas e conflitos da empresa.

De acordo com as informações obtidas na pesquisa, evidenciou-se que são encontradas

Revista de Gestão e Secretariado - GeSec, São Paulo, v. 5, n. 3, p 119-142, set./dez. 2014. 
dificuldades no processo decisório, mas a empresa busca planejar suas ações e para isso, faz monitoramento objetivando resultados satisfatórios. A constatação destes dados responde a segunda problemática da pesquisa.

Segundo as análises, foi possível verificar também que a relação da assessoria executiva contribui para o processo decisório com o fornecimento de informações de qualidade para a tomada de decisão e por também ser considerado agente facilitador, possuir conhecimentos e habilidades, visão sistêmica da organização, e assumir responsabilidades e riscos quando envolvido no processo. Isso é significativo, pois as decisões tomadas afetam a performance organizacional.

Por fim, as conclusões obtidas neste estudo foram de relevância para concretizar as teorias acadêmicas, no que diz respeito à atuação, a participação e a influência que o profissional de Secretariado Executivo exerce nos processos organizacionais.

Vale enfatizar que a pesquisa apresentou um estudo focado apenas na atuação de um profissional na organização. Estudos futuros envolvendo mais empresas podem ser realizados, objetivando avaliar a assessoria executiva no processo de tomada de decisão e assim buscar resultados mais abrangentes.

\section{REFERÊNCIAS}

Almeida,W. G.; Rogel, G. T. S. \& Shimoura, A. S. (2010). Mudanças de paradigmas na gestão do profissional de secretariado. São Paulo - GeSec. Revista Eletrônica. vol.1, n.1, pp.46-68, jan jun. Recuperado em 13 de outubro, 2013 de < http://revistagesec.org.br/ojs2.3.8/index.php/secretariado/article/view/3/72\#.UlrOSNJJN_Y>

Appolinário, F. (2009). Metodologia da ciência: filosofia e prática da pesquisa. São Paulo: Cengag Learning.

Beal, A. (2007). Gestão estratégica da informação: como transformar a informação e a tecnologia da informação em fatores de crescimento e de alto desempenho nas organizações (2a reimpr.). São Paulo: Atlas.

Beuren, I. M. (2000). Gerenciamento da informação: um recurso estratégico no processo de gestão empresarial. São Paulo: Atlas.

Bortolotto, M. F. P. \& Willlers, E. M. (2003). Profissional de secretariado Executivo: explanação das principais características que compõem o perfil. Revista Expectativa Secretariado Executivo. vol. 2, n.2. Recuperado em 9 de outubro, 2013 de 
Bruno, I. M. (2006). O poder de influência do profissional de Secretariado no processo decisório das organizações. Recuperado em 15 de março, 2013 de < http://www.fenassec.com.br/pdf/artigos_trab_cientificos_xvconsec_1lugar_a.pdf>

Cassarro, A. C. (2001). Sistemas de informações para tomada de decisões (3a ed. rev. ampl.). São Paulo: Pioneira.

Carvalho, R. E. (2011). A importância da tomada de decisão: e as dificuldades encontradas no momento de decidir. Monografia (Bacharelado em Administração) Universidade de Brasília, Brasília. Brasília - DF 2011. Recuperado em 15 de abril, 2013 de <http://bdm.bce.unb.br/handle/10483/3909>

Drucker, P. F \& Maciariello, J. A. (2007). O gerente eficaz em ação: uma agenda para fazer as coisas certas acontecerem. Rio de Janeiro: LCT.

Ferreira, A. F. A. (2010). Tomada de decisão: os aspectos do processo decisório e o uso da racionalidade na busca pelo sucesso nas decisões. Encontro de Ensino, pesquisa e extensão da Faculdade Senac. Recuperado em 2 de maio, 2013 de < http://tupi.fisica.ufmg.br/ michel/docs/Artigos_e_textos/Tomada_de_decisao/aspectos $\% 20 \mathrm{da} \% 2$ 0tomada\%20de\%20decisao.pdf>

Freitas, H. [et al.]. (1997). Informação e decisão: sistemas de apoio e seu impacto. Porto Alegre: Ortiz. Recuperado em: http://sphinxbrasil.com/revista/files/2011/12/LV-TEC-Ainfo_decisao.pdf $>$ Acesso em 27 abr. 2013.

Gil, A. C. (2009). Como elaborar projetos de pesquisa (4a ed.). São Paulo: Atlas. . (2010). Como elaborar projetos de pesquisa (5a ed.). São Paulo: Atlas.

Hair JR, J. F. et al. (2005). Fundamentos de métodos de pesquisa em administração. Porto Alegre : Bookman.

Hitt, M A,. Miller C.C. \& Colella, A. (2007). Comportamento organizacional: uma abordagem estratégica. Rio de Janeiro: LTC.

Lenzi, F. C.(Org.) \& Kiesel, M. D. (org.). (2009). O empreendedor de visão. São Paulo: Atlas.

Mascarenhas. M. H. S; Sepulveda, F. A. M. \& D’Assumpção, E. S. (2011). Sistema de gestão integrada: a atuação do secretário executivo. São Paulo - GeSec. Revista Eletrônica, vol. 2, n. 1, pp.177-192, jan.-jun. Recuperado em 25 de abril, 2013 de $<$ http://revistagesec.org.br/ojs2.3.8/index.php/secretariado/article/view/49.

Revista de Gestão e Secretariado - GeSec, São Paulo, v. 5, n. 3, p 119-142, set./dez. 2014. 
Minayo, M. C. de S.; Deslandes, S. F. \& Gomes, R. (org.) (2007). Pesquisa social: teoria método e criatividade (25a ed.) Petrópolis: Vozes.

Nonato, R. J. (2009). Epistemologia e teoria do conhecimento em secretariado executivo: a função da ciência da assessoria. Fortaleza: Expressão.

Oliveira, D. P. R. (2000). Sistemas, organizações e métodos: uma abordagem gerencial. (11 ${ }^{\mathrm{a}}$ ed.). São Paulo: Atlas.

Oliveira, M. M. (2010). Como fazer pesquisa qualitativa (3a ed.). Petrópolis: Vozes.

Porto, G. S. (2004). Características do processo decisório na cooperação empresa-universidade. Adm. Contemp. Vol. 8, n. 3 Curitiba jun.-set. Recuperado em $1^{\text {o }}$ de maio, 2013 de $<$ http://www.scielo.br/scielo.php?script=sci_arttext\&pid=S1415-65552004000300003 >

Richardson, R. J. (2008). Pesquisas sociais: métodos e técnicas (3a ed.) São Paulo: Atlas.

School, H. B. (2007). Tomando as melhores decisões. Rio de Janeiro: Elsevier.

Starec, C.; Gomes, E. \& Bezerra, J. (2005). Gestão estratégica da informação e inteligência competitiva. São Paulo: Saraiva.

Revista de Gestão e Secretariado - GeSec, São Paulo, v. 5, n. 3, p 119-142, set./dez. 2014. 